\title{
Yüksek Plastisiteli Killerin Stabilizasyonu ve Dokusal Değişimler: Bir Taramalı Elektron Mikroskobu (SEM) Çalışması
}

\author{
The Stabilization of High Plasticity Clays and Textural Changes: A Scanning Electron \\ Microscope (SEM) Study
}

\author{
Yasemin ASLAN TOPÇUOĞLU' , Zülfü GÜROCAK*b \\ Firat Üniversitesi, Mühendislik Fakültesi, Jeoloji Mühendisliği Bölümü, 23119, Elazı̆̆
}

• Geliş tarihi / Received: 08.04.2019 • Düzeltilerek geliş tarihi / Received in revised form: 08.05.2019 • Kabul tarihi / Accepted: 21.05 .2019

\begin{abstract}
$\ddot{O} z$
Stabilizasyon, puzolanik katkı malzemeleri kullanılarak killerin kıvam, dayanım ve sıkışma gibi geoteknik özelliklerinin iyileştirilmesidir. Kolay uygulanabilir ve ekonomik olması nedeniyle günümüzde en fazla tercih edilen yöntemlerden birisidir. Killi zeminlere belli oranlarda katkı malzemesi eklenerek uygulanan bu yöntem ile zemin içerisinde meydana gelen puzolanik reaksiyon sonucunda kilin geoteknik özellikleri iyileştirilebilmektedir. $\mathrm{Bu}$ yöntemde kullanılan katkı malzemeleri kireç, uçucu kül, silis dumanı, çimento, reçine gibi doğal olmayan puzolanlar ile birlikte tüf, volkanik kül, şeyl, diatomit gibi doğal puzolanik malzemeler de kullanılmaktadır. Ancak, daha ekonomik olması nedeniyle stabilizasyonun sadece doğal veya hem doğal hem de yapay puzolanlar kullanılarak yapılması önemlidir. Bu çalışmada, yapay ve doğal puzolanların kullanılması durumunda yüksek plastisiteli killerde meydana gelen dokusal değişimler incelenmiştir. Bu amaçla yapılan laboratuvar çalışmalarında, katkı malzemesi olarak sönmüş kireç, silis dumanı, uçucu kül ve tüf kullanılmıştır. Farklı tür ve oranda kullanılan katkı malzemelerinin etkisiyle kilin kıvamında ve dokusunda meydana gelen değişimler incelenmiştir. Yapılan çalışmalardan elde edilen sonuçlara göre, özellikle yapay ve doğal katkı malzemelerinin birlikte kullanıldığı örneklerde likit limit (LL) değerlerinin önemli ölçüde azaldığı belirlenmiştir. Tüm örneklerde Taramalı Elektron Mikroskobu (SEM) çalışmaları yapılmıştır. SEM çalışmaları ile elde edilen görüntüler, LL değerlerinde en fazla azalmanın meydana geldiği örneklerde puzolanik reaksiyon sonucunda önemli ölçüde topaklanmanın oluştuğunu göstermektedir. Bu örneklerde gelişen topaklanma sonucunda tane boyutları ve taneler arası boşluklarda artışlar belirlenmiştir. Ancak, LL değerindeki azalmanın sınırlı olduğu örneklerde topaklanma yeterince gelişmemiştir ve taneler daha plakamsı şekillidir.
\end{abstract}

Anahtar kelimeler: Doku, Kil, Puzolan, Stabilizasyon, Topaklanma

\begin{abstract}
Stabilization is the improvement of geotechnical properties of clays such as consistency, strength and compression by using pozzolanic additives. Today, it is one of the most preferred methods because it is easily applicable and economical. With this method, which is applied by adding certain amounts of additive to clayey soils, the geotechnical properties of clay can be improved by the pozzolanic reaction occurring in the soil. In this method, natural pozzolanic materials such as tuff, volcanic ash, shale, and diatomite have been used with the unnatural pozzolans such as lime, fly ash, silica fume, cement and resin as additives. However, it is important to make stabilization using only natural or both natural and unnatural pozzolans since it is more economical. In this study, the textural changes in high plasticity clay were investigated when using of natural and unnatural pozzolans. For this purpose, in the laboratory studies, slaked lime, silica fume, fly ash and tuff were used as additives. Variations in the consistency and texture of the clay due to the effects of different kinds and proportions of additives were investigated. According to the results obtained from the study, it was determined that the liquid limit (LL) values decreased significantly in the samples where the unnatural and natural additives were used together. Scanning Electron Microscopy (SEM) studies were performed in all samples. The images obtained by SEM studies showed that in the cases where the maximum decrease in LL values occurred, significant agglomeration occurred as a result of pozzolanic reaction. As a result of the agglomeration in these samples, increase in grain sizes and intergranular spaces were observed. However, in the samples where the reduction in LL is limited, agglomeration was not sufficiently developed and the grains are more plaque-shaped.
\end{abstract}

Keywords: Texture, Clay, Pozzolan, Stabilization, Agglomeration

\footnotetext{
*b Zülfü GÜROCAK; zgurocak@firat.edu.tr; Tel: (0532) 35536 47; orcid.org/0000-0002-1049-8346

${ }^{a}$ orcid.org/0000-0002-3135-5926
} 


\section{Giriş}

Stabilizasyon, mühendislik gereksinimlerini karşılamak için killi zeminlerin geoteknik özelliklerinin değiştirilmesi işlemidir (AttohOkine, 1995) ve killerin geoteknik özelliklerinin iyileştirilmesinde en yaygın olarak kullanılan yöntemlerden birisidir. $\mathrm{Bu}$ amaçla, farklı özelliklere sahip çok sayıda katkı malzemesi kullanılmaktadır. Kireç, çimento, uçucu kül, silis duman1, tüf, volkanik cam, volkanik kül, şeyl ve diatomit gibi katk1 malzemeleri zemine ait elementlerle kimyasal reaksiyona girerek kilin geoteknik özelliklerini iyileştirirken (Bell, 1996; Boardman vd., 2001; Kalkan ve Akbulut, 2004; Al-Rawas vd., 2005; Cuisinier vd., 2011; Harichane vd., 2011; Mahamedi ve Khemissa, 2013; Voottipruex ve Jamsawang, 2014; Azadegan vd., 2012; Mallela vd., 2004; Ramadas vd., 2011; Aksoy vd., 2008; Hilf, 1991; Sherwood, 1994; Little, 1995; Puppala vd., 2003; Asgari vd., 2015; Chu ve Kao, 1993; Goodarzi vd., 2015; Hossain ve Mol, 2011; Lin vd., 2013; Wang vd., 2013), jeofiber ve jeogrid gibi diğer katk1 malzemeleri ise fiziksel etkileri ile zeminin geoteknik özelliklerini iyileştirmektedir (Yang vd., 2012; Chong ve Kassim, 2014).

Zemindeki elementlerle kimyasal reaksiyona giren katk1 malzemeleri ilk olarak zeminin su içeriğinin azalmasına ve daha kolay işlenebilir hale gelmesine; uzun sürede ise zeminin dayanım, sıkışabilirlik ve duraylılık özelliklerinde iyileşmelere neden olmaktadır (Locat vd., 1990; Wild vd., 1996; Mallela vd., 2004; Geiman, 2005).

Jawad vd. (2014) yaptıkları çalışmada özellikle sönmüş kireç kullanılarak stabilize edilen killi zeminlerin geoteknik özelliklerinde meydana gelen değişimleri ve stabilizasyonda kireç kullanımının avantaj ve dezavantajlarını şu şekilde sıralamaktadır.

a) Zemini oluşturan daneler büyük boyutlu kümeler haline gelir ve böylece zemin dokusu değişir. $\mathrm{Bu}$ olaya topaklanma adı verilir. Topaklanma sonucunda zeminin boşluk oranı ve optimum su içeriği artarken, maksimum kuru yoğunluk ise azalır (Kinuthia vd., 1999).

b) Likit limitin azalması ve plastik limitin artması ile plastisite indisi azalır. Böylece zemin non-plastik özellik kazanabilir (Little vd., 1995; Mallela vd., 2004).

c) Zeminin dayanımı önemli ölçüde artar. Ancak, bu artış kür süresi ile birlikte zeminin pH'1, organik karbon içeriği, doğal drenaj, aşırı miktarda değiştirilebilir sodyum, kil mineralojisi, ayrışma derecesi, karbonatların varlığı, çıkarılabilir demir, silika-seskuioksit oranı ve silika-alümin oranına bağlıdır (Mallela vd., 2004).

d) Zeminin tekrarlı yüklere karşı gösterdiği direnç olarak tanımlanan yorulma dayanımında artış meydana gelir. Zeminlerde uygulanan gerilmenin statik dayanıma oranına ters olarak döngüsel yükleme sayıs1 artar. Böylece, stabilize edilmiş zeminde zamanla kazanılan dayanım, yorgunluk etkisini dengelemekte ve stabilize edilmemiş zemine göre yorgunluk dayanımının artmasını sağlamaktadır. Mallela vd. (2004) tekrarlı yükleme sonucu zamanla geliştirilen gücün, stres/dayanım oranını azalttığını, böylece yorulma dayanımını arttırdığını belirtmektedir.

e) Stabilizasyon sonucunda meydana gelen puzolanik reaksiyon ile zeminde sertleşme meydana gelmekte ve böylece zeminin çevre koşullarındaki değişikliklerden kaynaklanan 1slanma-kuruma ve donma-çözülme döngülerinin olumsuz etkilerine karşı koyma kabiliyeti olarak tanımlanan (duraylilık) durability artmaktadır (Thompson ve Dempsey, 1969).

f) Stabilizasyon sonucu zeminin şişme potansiyeli ve hacimsel değişimi azalmaktadır. Little vd. (1995) şişme potansiyeli ve şişme basıncında meydana gelen önemli miktardaki bu azalmanın, stabilizasyon sonucu zeminin plastisite indisindeki azalma ile ilişkili olduğunu belirtmektedir. Ayrıca, kür ve puzolonik reaksiyon da şişme potansiyelinin azalmasını sağlamaktadır (Dempsey ve Thompson, 1968; Thompson, 1969; Little vd., 1995).

g) Zeminlerin stabilizasyonu hakkındaki çalışmalar, stabilizasyonun zeminin permeabilitesi üstündeki etkisi hakkında pek fazla bilgi vermemektedir. Bazı çalışmalarda (Broms ve Boman, 1977; El-Rawi ve Awad, 1981; McCallister ve Petry, 1992; Rajasekaran ve Narasimha Rao, 2002; Nalbantoglu ve Tuncer, 2001; Khattab vd., 2008) stabilizasyon sonucunda zeminin hidrolik iletkenliğinin arttığı, bazı çalışmalarda ise (Onitsuka vd., 2001; Milburn ve Parsons, 2004; Alhassan, 2008) zeminin permeabilitesinin önemli ölçüde azaldığı ifade edilmektedir.

h) Stabilizasyon işleminin zeminin sıkışabilirliği üzerindeki etkilerini inceleyen araştırmacılar (Rajasekaran ve Rao, 1997; Tremblay vd., 2001; Rao ve Shivananda, 
2005; Locat vd., 1996; Tedesco, 2006) stabilizasyonda kullanılan malzeme miktarının artmasıyla zeminin ön konsolidasyon basıncının doğrusal olarak arttığını ve böylece zeminin sıkışabilirliğinin azaldığını belirtmektedir.

i) Kireçle yapılan stabilizasyonlarda zeminde zararlı kimyasal reaksiyonlar da ortaya çıkabilmektedir. Bu reaksiyonlardan birincisi kireç karbonasyonu, ikincisi ise toprakta bulunan sülfat tuzu ile reaksiyondur. Zemin kireçle veya çözünebilir sülfat tuzu içeren herhangi bir kalsiyum bazlı katkı maddesiyle işlendiğinde, büzülme, 1sınma ve dağılma meydana gelebilir ve bu da güç kaybına neden olabilir. (Mitchell, 1986; Hunter, 1988; Nair ve Little, 2011). Sridharan vd. (1995), sülfatın varlığının kireçle stabilize edilmiş zeminin sıkıştırılabilirliğini arttırdığını belirtmektedir. Mitchell (1986), Katz vd. (2001), Braga Reis (1981) ve Hunter (1988) ise zeminde meydana gelen en önemli olumsuz etkinin, zeminin mineralojisinde bulunan kalsiyum ve alüminyum arasındaki çözünür sülfat ve su varlığında etrenjit ve/veya tomasit mineralleri üreten kimyasal reaksiyonlardan kaynaklandığını ifade etmişlerdir. Araştırmacılar, etrenjit mineralinin zeminde kabarma ve şişmelere neden olduğunu belirtmektedirler.

Son yıllarda zeminlerin geoteknik özelliklerini iyileştirmek amaciyla reçine, köpük, emülsiyonlar, enzimler, asitler, sıvı polimerler ve endüstriyel atık gibi malzemeler de kullanılmaya başlanmıştır. $\mathrm{Bu}$ konuda yapılan çalışmalarda (Rauch vd., 2002; Santoni vd., 2002; Newman ve Tingle, 2004; Harris vd., 2006; Gilazghi vd., 2016; Naeini ve Ghorbanalizadeh, 2010, AlKhanbashi ve Abdalla, 2006; Zandieh ve Yasrobi, 2010; Ajalloein vd., 2013, Anagnostopoulos ve Papaliangas, 2012; Naeini vd., 2012; Anagnostopoulos vd., 2013; Mohammed ve Vipulanandan, 2013) bu tür malzemelerin zemin stabilizasyonunda başarılı bir şekilde kullanılabileceği belirtilmektedir. Stabilizasyonda çimento kullanılması durumunda ise zeminler daha gevrek hale gelebilmekte, dinamik yüklerin etkisiyle çatlakların oluşması kolaylaşabilmektedir (Little, 1992; Sebesta, 2005; Li, 2014).

Stabilizasyonda kullanılacak malzemenin ekonomik olması da önem taşımaktadır. Nitekim, kireç, çimento, silis dumanı gibi katkıların kullanımı stabilizasyon maliyetini artırmakta ve bu katk1 maddelerinin üretildiği tesisler karbon salınımına ve iklim değişikliğine neden olmaktadır (Imbabi vd., 2012).

$\mathrm{Bu}$ nedenlerden dolayı, killerin stabilizasyonunda kullanılacak malzemenin, zeminin geoteknik özelliklerini amaca uygun hale getirmesi ile birlikte ekonomik ve kolay elde edilebilir olmas1 da önemlidir. $\mathrm{Bu}$ konuda yapılan çalışmalarda (Bulut, 2007; Find1k, 2005; Kavlak, 2008; Keskin ve Çimen, 1997; Okucu, 1998) pomza, perlit ve tüf gibi malzemelerin zeminlerin stabilizasyonunda kullanılabilirliği araştırılmıştır. Elde edilen sonuçlar özellikle volkanik kül ve tüflerin zeminlerin stabilizasyonunda oldukça etkili olduğunu ve kullanılabileceğini göstermektedir.

$\mathrm{Bu}$ çalışmada katk1 malzemesi olarak kireç, silis duman1, uçucu kül ve asidik ve bazik karakterli tüfler seçilmiş ve stabilizasyon sonucunda yüksek plastisiteli kilde meydana gelen dokusal değişiklikler incelenmiştir. Stabilizasyon konusunda yapılan çalışmalar incelendiğinde, genel olarak kilin kıvam limitleri, jeokimyas1, dayanımı gibi özelliklerinin incelendiği görülmektedir. $\mathrm{Bu}$ çalışmalarda kilin dokusunda meydana gelen değişimlerin görüntüleme yöntemleri kullanılarak incelendiği çalışmalar oldukça kısıtlıdır. Bu çalışmada Taramalı Elektron Mikroskopu (SEM) çalışmaları yapılarak stabilizasyon sonrasında kilin dokusunda meydana gelen değişimler görüntülenmiştir.

\section{Deneysel Çalışmalar}

$\mathrm{Bu}$ çalışmada, katkı malzemelerinin yüksek plastisiteli killerin geoteknik özelliklerinde ve özellikle dokusunda meydana getirdiği değişimler incelenmiştir. $\mathrm{Bu}$ amaçla, katk1 malzemesi olarak asidik ve bazik karakterli tüf ile sönmüş kireç, silis dumanı ve uçucu kül kullanılmıştır. Çalışmalarda kullanılan bentonit Reşadiye (Tokat) kil ocağından, bazik tüf Ağın (Elazığ) bölgesinde yüzeyleme veren Karabakır Formasyonu'nundan, asidik karakterli tüf Gümüşhane bölgesinde yüzeyleme veren Kızılkaya Formasyonu'nundan, uçucu kül Afşin-Elbistan Termik Santrali'nden, silis dumanı ve sönmüş kireç ise piyasadan satın alınarak elde edilmiştir. $\mathrm{Bu}$ puzolanlar Birleştirilmiş Zemin Sınıflamasına (UCSC) göre yüksek plastisiteli kil $(\mathrm{CH})$ ile farklı oranlarda karıştırılmış ve kilin dokusal özelliklerinde meydana gelen değişimler Taramalı Elektron Mikroskobu (SEM) çalışmaları ile incelenmiştir. SEM çalışmaları Fırat Üniversitesi Merkez Laboratuvarı'nda (MERLAB) gerçekleştirilmiştir. 
$\mathrm{Bu}$ çalışmada gerçekleştirilen laboratuvar çalışmalarının ilk aşamasında katkısız kil ve belli oranlarda katkı katılan kil örnekleri hazırlanmış, bu örneklerde ASTM standartlarına göre kıvam limitleri (ASTM D 4318, 2017) ve optimum su içerikleri (ASTM D 698, 2012) belirlenmiştir. Bu deneyler Fırat Üniversitesi Jeoloji Mühendisliği Bölümü, Kaya-Zemin Mekaniği Laboratuvarı'nda gerçekleştirilmiştir.

Killerin stabilizasyonu konusunda yapılan çalışmalar (Little vd., 1995; Mallela vd., 2004), başarılı bir stabilizasyonun killerde likit limit (LL) ile plastisite indisinin (PI) azalmasına, plastik limitin (PL) ise artmasına ve böylece killi zeminin daha non-plastik özellik kazanmasına neden olduğunu göstermektedir. Yani, stabilizasyon sonrasında kıvam limitlerinde ortaya çıkan değişimler, kullanılan katk1 malzemesi ve katkı oranının stabilizasyon için uygun olduğuna işaret etmektedir. $\mathrm{Bu}$ çalışmada, en başarılı stabilizasyonun sağlandığ 1 örnekleri belirlemek amacıyla öncelikle kıvam limitleri belirlenmiştir. Stabilizasyon sonrasinda killi zemini plastisitesinde en fazla azalmanın meydana geldiği örnekler seçilerek, bu örneklerdeki doku değişimleri incelenmiştir. Gerçekleştirilen laboratuvar deneylerine ait sonuçlar Tablo 1'de verilmiştir.

Tablo 1. Katkısız ve katkılı kil örneklerinin kür öncesi kıvam limiti ve optimum su içeriği değerleri

\begin{tabular}{|c|c|c|c|c|c|c|}
\hline Grup & No & Örnek & LL (\%) & PL $(\%)$ & PI (\%) & $\mathrm{w}_{\mathrm{opt}}(\%)$ \\
\hline & 1 & $\mathrm{C}$ & 507 & 41 & 466 & 31.50 \\
\hline \multirow{3}{*}{ A } & 2 & $\mathrm{C}+\mathrm{SL} \% 5$ & 259 & 57 & 202 & 40.91 \\
\hline & 3 & $\mathrm{C}+\mathrm{SL} \% 10$ & 360 & 51 & 309 & 43.00 \\
\hline & 4 & $\mathrm{C}+\mathrm{SL} \% 20$ & 395 & 58 & 337 & 43.50 \\
\hline \multirow{3}{*}{ B } & 5 & $\mathrm{C}+\mathrm{BT} \% 5$ & 487 & 43 & 444 & 40.00 \\
\hline & 6 & $\mathrm{C}+\mathrm{BT} \% 10$ & 463 & 32 & 431 & 46.10 \\
\hline & 7 & $\mathrm{C}+\mathrm{BT} \% 20$ & 435 & 39 & 396 & 43.00 \\
\hline \multirow{3}{*}{$\mathrm{C}$} & 8 & $\mathrm{C}+\mathrm{AT} \% 5$ & 463 & 37 & 426 & 48.00 \\
\hline & 9 & $\mathrm{C}+\mathrm{AT} \% 10$ & 433 & 34 & 399 & 39.00 \\
\hline & 10 & $\mathrm{C}+\mathrm{AT} \% 20$ & 377 & 34 & 343 & 40.00 \\
\hline \multirow{4}{*}{ D } & 11 & $\mathrm{C}+\mathrm{AT} \% 5+\mathrm{SL} \% 5$ & 253 & 52 & 201 & 54.00 \\
\hline & 12 & $\mathrm{C}+\mathrm{AT} \% 10+\mathrm{SL} \% 5$ & 350 & 54 & 296 & 69.00 \\
\hline & 13 & $\mathrm{C}+\mathrm{AT} \% 5+\mathrm{SL} \% 10$ & 340 & 55 & 285 & 65.00 \\
\hline & 14 & $\mathrm{C}+\mathrm{AT} \% 10+\mathrm{SL} \% 10$ & 302 & 56 & 246 & 70.00 \\
\hline \multirow{4}{*}{$\mathrm{E}$} & 15 & $\mathrm{C}+\mathrm{BT} \% 5+\mathrm{SL} \% 5$ & 379 & 55 & 324 & 50.00 \\
\hline & 16 & $\mathrm{C}+\mathrm{BT} \% 10+\mathrm{SL} \% 5$ & 430 & 52 & 378 & 53.00 \\
\hline & 17 & $\mathrm{C}+\mathrm{BT} \% 5+\mathrm{SL} \% 10$ & 305 & 54 & 251 & 56.00 \\
\hline & 18 & $\mathrm{C}+\mathrm{BT} \% 10+\mathrm{SL} \% 10$ & 325 & 53 & 272 & 57.00 \\
\hline \multirow{3}{*}{$\mathrm{F}$} & 19 & $\mathrm{C}+\mathrm{SF} \% 5$ & 440 & 36 & 404 & 48.50 \\
\hline & 20 & $\mathrm{C}+\mathrm{SF} \% 10$ & 460 & 37 & 423 & 61.00 \\
\hline & 21 & $\mathrm{C}+\mathrm{SF} \% 20$ & 370 & 33 & 337 & 64.00 \\
\hline \multirow{4}{*}{ G } & 22 & $\mathrm{C}+\mathrm{AT} \% 5+\mathrm{SF} \% 5$ & 442 & 41 & 401 & 49.50 \\
\hline & 23 & $\mathrm{C}+\mathrm{AT} \% 5+\mathrm{SF} \% 10$ & 421 & 35 & 386 & 48.00 \\
\hline & 24 & $\mathrm{C}+\mathrm{AT} \% 10+\mathrm{SF} \% 5$ & 455 & 31 & 424 & 56.80 \\
\hline & 25 & $\mathrm{C}+\mathrm{AT} \% 10+\mathrm{SF} \% 10$ & 399 & 32 & 367 & 50.00 \\
\hline \multirow{4}{*}{$\mathrm{H}$} & 26 & $\mathrm{C}+\mathrm{BT} \% 5+\mathrm{SF} \% 5$ & 403 & 38 & 365 & 60.00 \\
\hline & 27 & $\mathrm{C}+\mathrm{BT} \% 10+\mathrm{SF} \% 5$ & 422 & 41 & 381 & 47.00 \\
\hline & 28 & $\mathrm{C}+\mathrm{BT} \% 5+\mathrm{SF} \% 10$ & 417 & 37 & 380 & 65.00 \\
\hline & 29 & $\mathrm{C}+\mathrm{BT} \% 10+\mathrm{SF} \% 10$ & 379 & 43 & 336 & 67.00 \\
\hline \multirow{3}{*}{ I } & 30 & $\mathrm{C}+\mathrm{FA} \% 5$ & 348 & 56 & 292 & 41.00 \\
\hline & 31 & $\mathrm{C}+\mathrm{FA} \% 10$ & 246 & 54 & 192 & 42.88 \\
\hline & 32 & $\mathrm{C}+\mathrm{FA} \% 20$ & 341 & 55 & 286 & 43.03 \\
\hline \multirow{4}{*}{$\mathrm{J}$} & 33 & $\mathrm{C}+\mathrm{AT} \% 5+\mathrm{FA} \% 5$ & 340 & 37 & 303 & 52.40 \\
\hline & 34 & $\mathrm{C}+\mathrm{AT} \% 10+\mathrm{FA} \% 5$ & 321 & 39 & 282 & 50.00 \\
\hline & 35 & $\mathrm{C}+\mathrm{AT} \% 5+\mathrm{FA} \% 10$ & 236 & 44 & 192 & 56.00 \\
\hline & 36 & $\mathrm{C}+\mathrm{AT} \% 10+\mathrm{FA} \% 10$ & 200 & 43 & 157 & 52.50 \\
\hline \multirow{4}{*}{ K } & 37 & $\mathrm{C}+\mathrm{BT} \% 5+\mathrm{FA} \% 5$ & 320 & 42 & 278 & 48.00 \\
\hline & 38 & $\mathrm{C}+\mathrm{BT} \% 10+\mathrm{FA} \% 5$ & 313 & 46 & 267 & 51.50 \\
\hline & 39 & $\mathrm{C}+\mathrm{BT} \% 5+\mathrm{FA} \% 10$ & 248 & 31 & 217 & 54.00 \\
\hline & 40 & $\mathrm{C}+\mathrm{BT} \% 10+\mathrm{FA} \% 10$ & 213 & 37 & 177 & 50.00 \\
\hline \multicolumn{2}{|c|}{$\mathrm{Kil}-\mathrm{C}$} & Asidik Tüf - AT & \multicolumn{3}{|c|}{ Bazik Tüf-BT } & \\
\hline Uçucu & - FA & Sönmüş Kireç -SL & & Duman1 & & \\
\hline
\end{tabular}


Laboratuvar deney sonuçlarına göre, katkısız kilin (C) LL değeri \%507, PL değeri ise \%41 dir. Karışımlara (Grup A - K) ait kıvam limitleri değerlerine bakıldığında LL değerlerinin \% 200 487 arasında, PL değerlerinin ise \% 31 - 58 arasında değiştiği görülmektedir. Farklı oranlarda ve farklı türlerde katkı malzemesinin kullanılması durumunda kilin LL değerleri azalırken PL değerlerinde az da olsa bir artış söz konusudur. Tablo 1'e göre her bir grupta LL değerlerinde en fazla azalmayı sağlayan karışımlar 2, 7, 10, 11,
$17,21,25,29,31,36$ ve 40 numaral1 karışımlardır.

İkinci aşamada, 2, 7, 10, 11, 17, 21, 25, 29, 31, 36 ve 40 numaralı örnekler optimum su içeriği $\left(\mathrm{w}_{\text {opt }}\right)$ değerinde sıkıştırılmış ve hazırlanan örnekler 28 günlük küre tabi tutulmuştur. Örneklerin kür sonrası LL değerleri yeniden belirlenmiştir. Örneklerin kür öncesi ve kür sonrası LL değerleri Tablo 2'de, meydana gelen \% değişim oranları ise Tablo 3'te verilmiştir.

Tablo 2. Kür öncesi ve kür sonrası kıvam limiti değerleri

\begin{tabular}{clcccccc}
\hline \multirow{2}{*}{ No } & \multirow{2}{*}{ Önek } & \multicolumn{3}{c}{ Kür öncesi } & \multicolumn{3}{c}{ Kür sonras1 } \\
\cline { 3 - 7 } & & $\begin{array}{c}\text { LL } \\
(\%)\end{array}$ & $\begin{array}{c}\text { PL } \\
(\%)\end{array}$ & $\begin{array}{c}\text { PI } \\
(\%)\end{array}$ & $\begin{array}{c}\text { LL } \\
(\%)\end{array}$ & $\begin{array}{c}\text { PL } \\
(\%)\end{array}$ & $\begin{array}{c}\text { PI } \\
(\%)\end{array}$ \\
\hline 1 & C & 507 & 41 & 466 & 480 & 42 & 438 \\
2 & C + SL \%5 & 259 & 57 & 202 & 240 & 59 & 181 \\
7 & C + BT \%20 & 435 & 39 & 396 & 410 & 43 & 367 \\
10 & C + AT \%20 & 377 & 34 & 343 & 360 & 37 & 323 \\
11 & C + AT \%5 + SL \%5 & 253 & 52 & 201 & 193 & 54 & 139 \\
17 & C + BT \%5 + SL \%10 & 305 & 54 & 251 & 200 & 57 & 143 \\
21 & C + SF \%20 & 370 & 33 & 337 & 360 & 35 & 325 \\
25 & C + AT \%10 + SF \%10 & 399 & 32 & 367 & 350 & 41 & 309 \\
29 & C + BT \%10 + SF \%10 & 379 & 43 & 336 & 360 & 43 & 317 \\
31 & C + FA \%10 & 246 & 54 & 192 & 235 & 56 & 179 \\
36 & C + AT \%10 + FA \%10 & 200 & 43 & 157 & 192 & 44 & 148 \\
40 & C + BT \%10 + FA \%10 & 213 & 37 & 177 & 204 & 43 & 161 \\
\hline
\end{tabular}

Tablo 3. Kür öncesi ve kür sonrası LL değerlerinde meydana gelen \% değişimler

\begin{tabular}{clcc}
\hline \multirow{2}{*}{ No } & Örnek & Kür öncesi & Kür sonras 1 \\
\cline { 3 - 4 } & & LL & LL \\
\cline { 3 - 4 } \% değişim & \% değişim \\
\hline 1 & C & - & -5.33 \\
2 & C + SL \%5 & -48.92 & -52.66 \\
7 & C + BT \%20 & -14.20 & -19.13 \\
10 & C + AT \%20 & -25.64 & -28.99 \\
11 & C + AT \%5 + SL \%5 & -50.10 & -61.93 \\
17 & C + BT \%5 + SL \%10 & -39.84 & -60.55 \\
21 & C + SF \%20 & -27.02 & -28.99 \\
25 & C + AT \%10 + SF \%10 & -21.30 & -30.97 \\
29 & C + BT \%10 + SF \%10 & -25.25 & -28.99 \\
31 & C + FA \%10 & -51.48 & -53.65 \\
36 & C + AT \%10 + FA \%10 & -60.55 & -62.13 \\
40 & C + BT \%10 + FA \%10 & -57.99 & -59.76 \\
\hline
\end{tabular}

Tablo 3'e göre; katkısız kilin kür sonrası LL değeri kür öncesi LL değerine göre \%5.33 oranında azalmaktadır. Ayrıca, katkılı örneklerin kür öncesi LL değerleri katkısız kilin kür öncesi LL değerlerine göre \%14.2 ile \%60.55 oranında azalırken, kür sonrası LL değerlerindeki azalma oran1 \%19.13 ile \%62.13 arasında değişmektedir. $\mathrm{Bu}$ durum, kullanılan katk1 malzemesi ile birlikte kür süresinin de LL değerlerinin azalmasında ve dolayısıyla kilin geoteknik özelliklerinin iyileşmesinde etkili olduğunu göstermektedir.

LL değerlerinde en fazla azalmanın meydan geldiği örnekler $2,11,17,31,36$ ve 40 numaralı örneklerdir. $\mathrm{Bu}$ örneklerden 2 ve 31 nolu örneklerde yapay (sönmüş kireç ve uçucu kül), 11, 17,36 ve 40 numaralı örneklerde ise hem yapay hem de doğal puzolanik malzeme (bazik ve asidik 
karakterli tüf) kullanılmıştır. Bu örneklerin kür sonrası LL değerlerinde meydana gelen azalma $\% 52.66$ ile \%62.13 oranında değişirken, $7,10,21$, 25 ve 29 nolu örneklerin kür sonras1 LL değerlerinde meydana gelen azalma oranı \%19.13 ile $\% 30.97$ oranında değişmektedir.

Sadece silis dumanı, asidik tüf veya bazik tüfün katk1 malzemesi kullanılmas1 durumunda $(7,10$ ve 21 nolu örnekler) kilin LL değerlerindeki azalma sinırlı olmaktadır. Benzer durum silis dumanı ile asidik ve bazik tüflerin birlikte kullanıldığı 25 ve 29 nolu örnekler içinde geçerlidir. Bu sonuçlar, silis dumanının puzolanik özelliğinin kireç ve uçucu küle göre daha az olduğunu göstermektedir. Silis dumanının asidik ve bazik tüfler ile birlikte kullanılması durumunda ise LL değerlerinde daha fazla bir azalma olmasına karşın, diğer örneklerdeki azalma oranı ile karşılaştırıldığında bu oranın çok yetersiz olduğunu söylemek mümkündür.

LL değerinde en fazla azalmanın (\%62.13) belirlendiği 36 nolu örnekte katk1 malzemesi olarak \%10 asidik tüf ve $\% 10$ uçucu kül kullanılmıştır. Sadece sönmüş kireç ve uçucu külün kullanıldığı örneklerde (2 ve 31 nolu örnekler) LL değerlerindeki azalma oranı \%50 civarında iken, hem doğal hem de yapay puzolanların kullanıldığ 1 örneklerde $(11,17,36$ ve 40 nolu örnekler) bu oran \% 60'lar civarındadır. $\mathrm{Bu}$ sonuç, iki tip katkı malzemesinin birlikte kullanılması durumunda daha iyi sonuçlar elde edilebileceğini göstermektedir.

Mikro yapı zeminlerin mühendislik davranışını etkileyen en önemli faktörlerden birisidir. $\mathrm{Bu}$ konuda yapılan çalışmalarda (Collins, 1984; Terrei vd., 1984; Push, 1979; Mitchell, 1993; Türköz, 2009) farklı katkı malzemelerinin kullanıldığı stabilizasyon sonrasında, kilin dokusal olarak değiştiği belirlenmiştir. En önemli değişim ise stabilizasyon sonrasında meydana gelen topaklanma sonucunda tane boyundaki büyümedir. Böylece, kil iri taneli malzeme gibi davranmaya başlamakta, boşluk oranı artmakta, optimum su içeriği artarken, kuru yoğunluğu azalmakta, serbest basınç dayanımı (UCS) ve Kaliforniya Taşıma Oranı (CBR) ise artış göstermektedir (Jawad vd., 2014).

$\mathrm{Bu}$ çalı̧̧mada, katk11ı örneklerin dokusunda meydana gelen değişimleri de görebilmek amacıyla, SEM çalışmaları yapılmıştır. Farklı katk1 malzemeleri kullanılarak stabilize edilen örnekler 28 günlük kür sonrası SEM çalışmaları ile incelenmiş ve elde edilen görüntüler katkısız kile ait görüntü ile karşılaştırılarak dokuda meydana gelen değişimler ortaya konulmaya çalışılmıştır.

SEM; minerallerin morfoloji, boyut, şekil ve birbirleriyle olan ilişkileri olarak tanımlanan dokunun en iyi şekilde incelenebildiği yöntemlerden birisidir. $\mathrm{Bu}$ yöntemde görüntü, yüksek voltaj ile hızlandırılmış elektronların örnek üzerine odaklanması, bu elektron demetinin örnek yüzeyinde taratılması sırasında elektron ve örnek atomları arasında oluşan çeşitli girişimler sonucunda meydana gelen etkilerin uygun algılayıcılarda toplanması ve sinyal güçlendiricilerden geçirildikten sonra katot 1şınları tüpünün ekrana aktarılmasıyla elde edilir. Algılayıcılardan gelen sinyaller dijital sinyallere çevrilip bilgisayar monitörüne verilmekte ve böylece görüntü elde edilmektedir. $\mathrm{Bu}$ çalışmadan elde edilen görüntüler Şekil 1 ve 2'de verilmiş ve stabilizasyon sonucunda kilde meydana gelen dokusal değişimler irdelenmiştir.

Katkılı örneklerden SEM çalışmaları ile elde edilen görüntüler katkısız kilin görüntüsü ile karş1laştırıldığında; LL değerinde en fazla azalma oranının belirlendiği $2,11,17,31,36$ ve 40 nolu örneklere ait görüntülerde, tanelerin katkısız kile oranla daha iri ve taneler arasındaki boşlukların ise daha fazla olduğu açıkça görülmektedir. $\mathrm{Bu}$ dokusal değişimin nedeni stabilizasyon sonrasında gelişen topaklanma olayıdır. LL değerlerinde meydana gelen azalma oran1 \%19.13-30.97 arasinda olan 7, 10, 21, 25 ve 29 nolu örneklere ait görüntüler katkısız kile ait görüntüler ile karşılaştırıldığında; danelerin daha plakamsı özellikte ve taneler arası boşlukların daha az olduğu görülmektedir.

$\mathrm{Bu}$ görüntüler, LL değerlerinde meydana gelen azalmanın doğrudan topaklanma ile ilişkili olduğunu, topaklanmanın iyi gelişmesi sonucu tane boyunun büyüdüğünü ve böylece kil daha iri taneli örneğin silt gibi davrandığını ve LL değerini azaldığını göstermektedir.

\section{Sonuçlar}

Yapılan çalışmalar sonucunda elde edilen sonuçları aşağıdaki gibi kısaca sıralamak mümkündür.

- Stabilizasyonda farklı tür ve oranlarda kullanılan katk1 malzemelerinin etkisiyle, kilin LL değerlerinde önemli azalmalar, PL değerlerinde ise önemsenemeyecek kadar az artışlar gerçekleşmiştir. Artan katkı oranı kilin plasitistesini düşürmekte ve non-plastik özellik kazanmasına yol açmaktadır. 


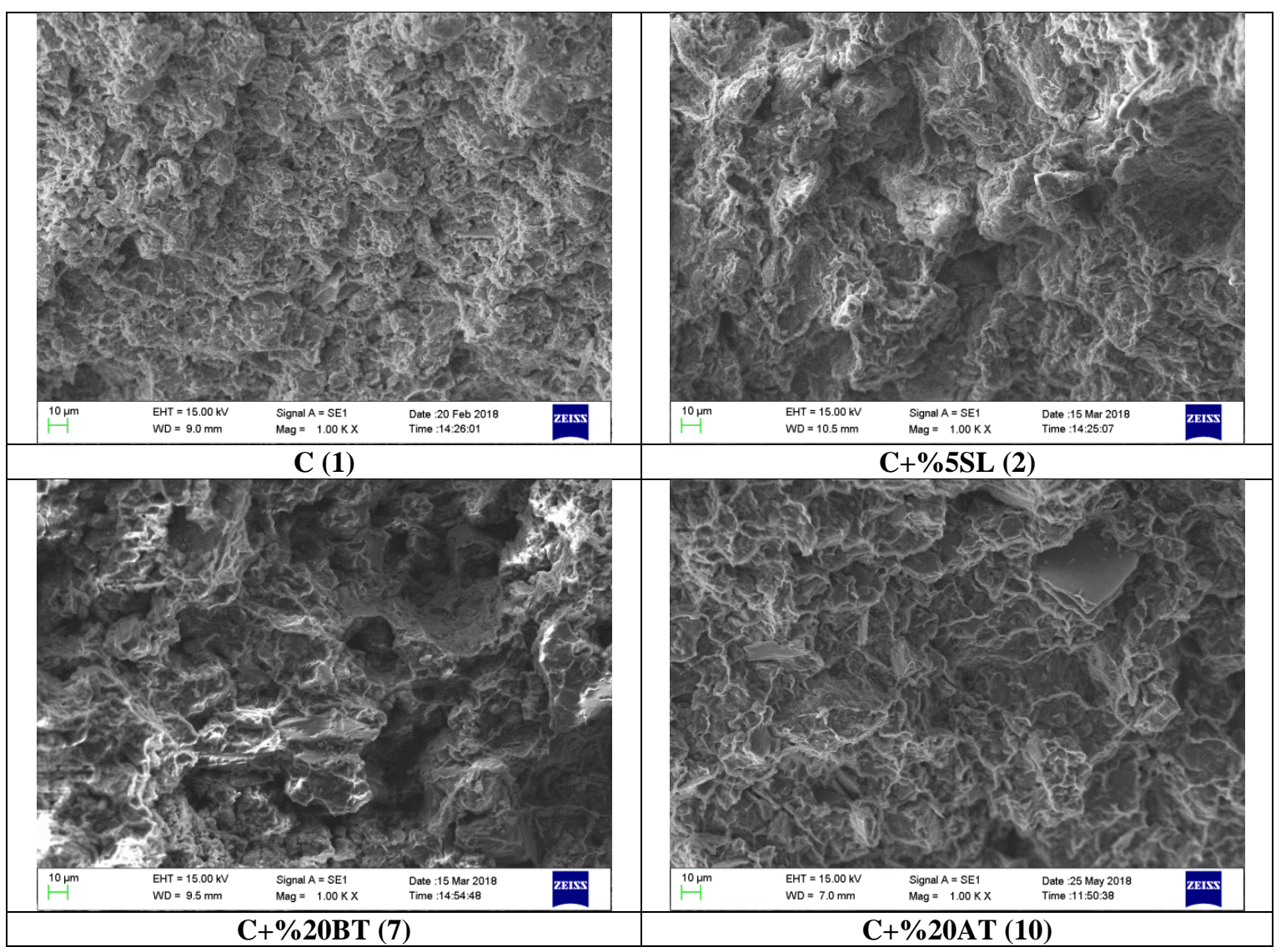

Şekil 1. 1, 2, 7 ve 10 nolu örneklere ait SEM görüntüleri

- 28 günlük kür sonrasında belirlenen LL değerlerine göre katkısız kilin LL değeri \%5.33 oranında azalma göstermiştir. Katkılı killerin kür öncesi LL değerlerindeki azalma ise \%14.20-60.55 oranında iken, azalma oranı kür sonrasında \%19.13 ile \%62.13 arasında gerçekleşmiştir. Bu sonuçlar kür süresinin stabilizasyonda önemli bir etken olduğunu göstermektedir.

- Sadece sönmüş kireç ve uçucu külün kullanıldığg örnekler ile bunların asidik ve bazik karakterli tüfler ile birlikte kullanıldığ örneklerin kür sonras1 LL değerlerindeki azalma oran1 \%52.66 ile \%62.13 arasinda gerçekleşmiştir. Katkı malzemesi olarak sadece silis duman1, asidik tüf veya bazik tüfün kullanılması durumunda $(7,10$ ve 21 nolu örnekler) kür sonrası LL değerlerindeki azalma \%19.13-28.99 oranındadır. Silis dumanı ile bazik ve asidik tüflerin birlikte kullanıldığ 1 örneklerde ( 25 ve 29 nolu örnekler) ise kür sonrası LL değerlerindeki azalma oran1 \%28.99-30.97 olarak belirlenmiştir. $\mathrm{Bu}$ değerler killerin stabilizasyonunda kireç ve uçucu külün silis dumanına gore daha etkili olduğunu göstermektedir. Silis dumanının asidik ve bazik tüfler ile birlikte kullanılması durumunda kür sonrası LL değerlerinde meydana gelen azalma oranında çok az bir artış görülmüştür. Ancak, diğer örneklerdeki azalma oranı ile karşılaştırıldığında bu azalma miktarı çok yetersizdir. Bu sonuçlar kireç ve uçucu kül ile birlikte asidik ve bazik tüfün de katkı malzemesi olarak kullanılması durumunda başarılı bir stabilizasyonun gerçekleştirilebileceğini göstermektedir. Böylece çevreye olan olumsuz etkileri olan kireç ve uçucu külün stabilizasyonda kullanımını da azalmış olacaktır.

- Kür sonrası LL değerinde en fazla azalma oranının belirlendiği $2,11,17,31,36$ ve 40 nolu örneklerde yapılan SEM çalışmalarında tanelerin katkısız kile oranla daha iri ve taneler arasındaki boşlukların ise daha fazla olduğu görülmüştür. Kür sonras1 LL değerlerindeki azalmanın sinırlı olduğu örneklere ait görüntülerde ise tanelerarası boşukların daha az ve tanelerin daha plakamsı özellikte olduğu belirlenmiştir.

- Stabilizasyon sonucunda kilde meydana gelen bu dokusal değişim nedeni; katkı ve kür sonrasinda kilde meydana gelen, kilin daha iri taneli bir zemin gibi davranmasına ve LL değerinin azalmasına yol açan topaklanmadir. 


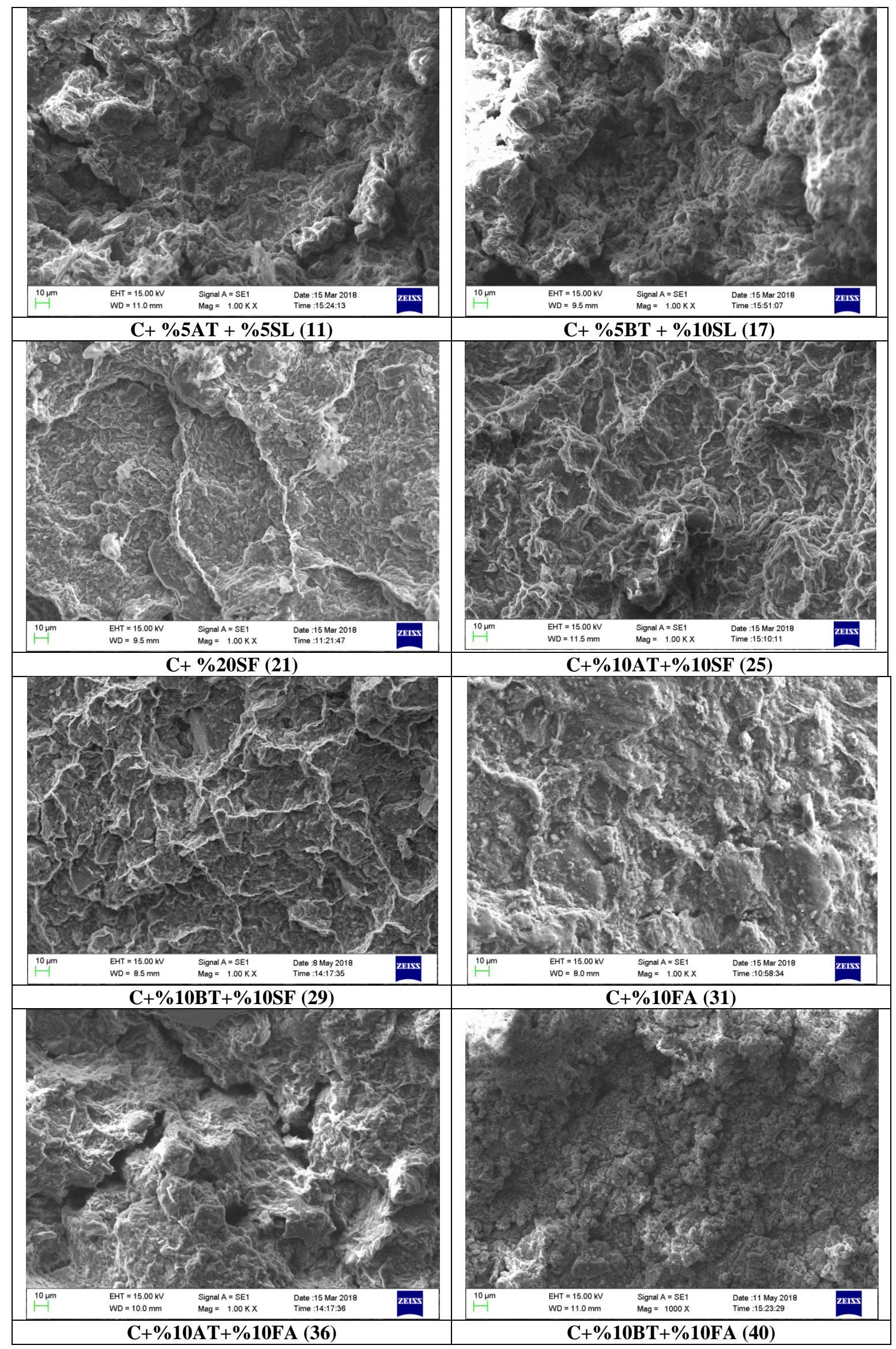

Şekil 2. 11, 17, 21, 25, 29, 31, 36 ve 40 nolu örneklere ait SEM görüntüleri 


\section{Kaynaklar}

Ajalloeian, R., Matinmanesh, H., Abtahi, S., Rowshanzamir, M., 2013. Effect of polyvinyl acetate grout injection on geotechnical properties of fine sand, Geomechanics and Geoengineering, 8(2), 86-96.

Aksoy, H.S., Yılmaz, M., Akarsu, E.E., 2008. Killi Bir Zeminin Tunçbilek Uçucu Külü Kullanılarak Stabilizasyonu, Doğu Anadolu Bölgeleri Araştırmaları.

Alhassan, M., 2008. Permeability of lateritic soil treated with lime and rice husk ash. Assumption Univ., J. Thailand, 12(2): 115-120.

Al-Khanbashi, A. and Abdalla, S., 2006. Evaluation of three waterborne polymers as stabilizers for sandy soil, Geotechnical and Geological Engineering, 24(6), 1603-1625.

Al-Rawas, A.A., Hugo, A.W. and Al-Sami, H., 2005. Effect of lime, cement and artificial pozzolan on the swelling potential of an expansive soil from Oman", Building \& Environment, 40, Elsevier, 267-281.

Anagnostopoulos, C. and Papaliangas, T., 2012. Experimental investigation of epoxy resin and sand mixes, Journal of Geotechnical and Geoenvironmental Engineering, 138(7), 841849.

Anagnostopoulos, C., Kandiliotis, P., Lola M., Karavatos S., 2013. Effect of epoxy resin mixtures on the physical and mechanical properties of sand, Research Journal of Applied Sciences, Engineering and Technology, 7(17), 3478-3490.

Asgari, M. R., Dezfuli, A. Baghebanzadeh, Bayat, M., 2015. Experimental Study on Stabilization of a Low Plasticity Clayey Coil With Cement/Lime, Arabian Journal of Geosciences 8(3), 14391452.

ASTM, 2012. Standard Test Methods for Laboratory Compaction Characteristics of Soil Using Standard Effort, (ASTM D698- 12e2). ASTM International, West Conshohocken, PA.

ASTM, 2017. Standard Test Methods for Liquid Limit, Plastic Limit, and Plasticity Index of Soils, (ASTM D4318-17e1). ASTM International, West Conshohocken, PA.

Attoh-Okine, N.O., 1995. Lime treatment of laterite soils and gravels-revisited. Constr. Build. Mater., 9(5): 283-287.

Azadegan, O., Jafari, S.H. and Li, J., 2012. Compaction characteristics and mechanical properties of lime/cement treated granular soils. Electron. J. Geotech. Eng., 17: 2275-2284.

Bell, F., 1996. Lime stabilization of clay minerals and soils. Eng. Geol., 42(4): 223-237.

Boardman, D.I., Glendinning, S. and Rogers, C.D.F. 2001. "Development of stabilization and solidification in lime-clay mixes", Geotechnique, 51(6), 533-543.

Braga Reis, M.O., 1981. Formation of expansive calcium sulphoaluminate by the action of the sulphate ion on weathered granites in a calcium hydroxide-saturated medium. Cement Concrete Res., 11(4): 541-547.

Broms, B. and Boman P., 1977. Stabilization of Soil with Lime-soil Columns. Design Handbook, 2nd Edn., Royal Institute of Technology, Stockholm, Sweden.

Bulut, Ü., 2007. Perlitin Puzolanik Aktivitesi, İstanbul Teknik Üniversitesi Fen Bilimleri Enstitüsü, Doktora Tezi, 162s.

Chong, S.Y. and Kassim, K.A., 2014. Consolidation characteristics of lime column and Geotextile Encapsulated Lime Column (GELC) stabilized pontian marine clay. Electron. J. Geotech. Eng., 19A: 129-141.

Chu, S.C. and Kao, H.S., 1993. A Study of Engineering Propeities of A Clay Modified By Fly Ash and Slag, Fly Ash for Soil İmprovement, Geotechnical Special Publication, No:36, s. 89100, Ed.:Sharp K.D., ASCE, Newyork.

Collins, K., 1984. "Characterization of expansive soil microfabric." In Proceedings of the 5th International Conference on Expansive Soils, Adelaide, South Australia, pp. 37-41.

Cuisinier, O., Auriol, J-C., Le Borgne, T. and Deneele, D., 2011. "Microstructure and hydraulic conductivity of a compacted lime-treated soil", Eng. Geol., 123(3), 187-193.

Dempsey, B.J. and Thompson, M.R., 1968. Durability Properties of Lime-soil Mixtures. Highway Research Record No. 235, National Research Council, Washington D.C.

El-Rawi, N.M. and Awad A.A.A., 1981. Permeability of lime stabilized soils. T. Eng. J., 107(1): 2535 .

Findık, S., 2005. Karayolu esnek üstyapıları alttemel tabakasının stabilizasyonunda hafif agregaların kullanılabilirliği, Süleyman Demirel Üniversitesi Fen Bilimleri Enstitüsü Yüksek Lisans tezi, Isparta.

Geiman, C.M., 2005. Stabilization of soft clay subgrades in Virginia phase I laboratory study. 
M.A. Thesis, Virginia Polytechnic Institute and State University.

Gilazghi, S., Huang, J., Rezaeimalek, S., Bin-Shafique, S., 2016. Stabilizing sulfate-rich high plasticity clay with moisture activated polymerization, Engineering Geology, 211, 171-178.

Goodarzi, A. R., Goodarzi, Sh., Akbari, H. R., 2015. Assessing Geo-Mechanical and MicroStructural Performance of Modified Expansive Clayey Soil by Silica Fume as Industrial Waste, Iranian Journal of Science And TechnologyTransactions of Civil Engineering, 39 (C2), 333-350.

Harichane, K., Ghrici, M., Khebizi, W. and Missoum, H., 2011. "Effet de la combinaison de la chaux et de la pouzzolane naturelle sur la durabilité des sols argileux", Proceedings of 29th meeting of AUGC-Tlemcen, Algeria, 29-31 mai, 2, 6575 .

Harris, P., Holdt, P., Sebesta, S., 2006. Recommendations for Stabilization of HighSulfate Soils in Texas, Federal Highway Administration, Texas Transportation Institute, Texas A\&M University, FHWA/TX-06/0-42403.

Hilf, J., 1991. Compacted fill, in: H. Fang (Ed.), Foundation Engineering Handbook, Van Nostrand Reinhold, NewYork, ABD.

Hossain, K. M. A., Mol, L., 2011. Some Engineering Properties of Stabilized Clayey Soils Incorporating Natural Pozzolans and Industrial Wastes, Construction and Building Materials, 25(8), 3495-3501.

Hunter, D., 1988. Lime-induced heave in sulfatebearing clay soils. J. Geotech. Eng., 114(2): 150-167.

Imbabi, M., Carrigan, C., McKenna, S., 2012. Trends and developments in green cement and concrete technology", International Journal of Sustainable Built Environment, 1(2), 194-216.

Jawad, I.T., Taha, M.R., Majeed, Z.H., and Khan, T.A., 2014. Soil Stabilization Using Lime: Advantages, Disadvantages and Proposing a Potential Alternative, Research Journal of Applied Sciences, Engineering and Technology 8(4): 510-520.

Kalkan, E. and Akbulut, S., 2004. "The positive effects of silica fume on the permeability, swelling pressure and compressive strength of natural clay liners”, Eng. Geol., 73(1-2), 145-156.

Katz, L., Rauch, A., Liljestrand, H., Harmon, J., Shaw, K., Albers, H., 2001. Mechanisms of soil stabilization with liquid ionic stabilizer,
Transportation Research Records: Journal of Transportation Research Board, 1757, 50-57.

Kavlak, Y., 2008. Isparta Gelincik pomzasının karayolu esnek üstyapıları taban zemini stabilizasyonunda kullanımı, Süleyman Demirel Üniversitesi Fen Bilimleri Enstitüsü Yüksek Lisans tezi, Isparta.

Keskin, S.N., Çimen, Ö., 1997. Killi zeminlerin mühendislik özelliklerinin iyileştirilmesinde pomza kullanımının araştırılması, I. Isparta Pomza Sempozyumu, 97-101.

Khattab, S.A.A., Al-Juari, K.A.K. and Al-Kiki, I., 2008. Strength, durability and hydraulic properties of clayey soil stabilized with lime and industrial waste lime. Al-Rafidain Eng., 16(1): 102-116.

Kinuthia, J.M., Wild, S. and Jones G.I., 1999. Effects of monovalent and divalent metal sulphates on consistency and compaction of lime-stabilised kaolinite. Appl. Clay Sci., 14(1-3): 27-45.

Li, X.J., 2014. Shrinkage Cracking of Soils and Cementitiously-Stabilized Soils: Mechanisms and Modeling, Ph.D. thesis, Washington State University, ABD.

Lin, B., Cerato, Amy B., Madden, Andrew S., Madden, Megan E Elwood., 2013. Effect of Fly Ash on the Behavior of Expansive Soils: Microscopic Analysis, Environmental Engineering Geoscience, 19(1), 85-94.

Little, D., 1995. Stabilization of Pavement Subgrades Base Courses with Lime, Lime Association of Texas, ABD.

Little, D.N., 1992. Comparison of in-situ resilient moduli of aggregate base courses with and without low percentages of lime stabilization, ASTM Special Technical Publication, 1135, 822.

Little, D.N., Scullion, T., Kota, P.B.V.S. and Bhuiyan, J., 1995. Guidelines for mixture design and thickness design for stabilized bases and subgrades. Texas A and M University, Austin, Texas.

Locat, J., Berube, M.A. and Choquette, M., 1990. Laboratory investigations on the lime stabilization of sensitive clays: Shear strength development. Can. Geotech. J., 27(3): 294-304.

Locat, J., Trembaly, H. and Leroueil S., 1996. Mechanical and hydraulic behaviour of a soft inorganic clay treated with lime. Can. Geotech. J., 33(4): 654-669. 
Mahamedi, A. and Khemissa, M., 2013. "Cement stabilization of compacted expansive clay", Online j. Sci. Technol., 3(1), 33-38.

Mallela, J., Harold Von Quintus, P., Smith, K.L. and Consultants, E., 2004. Consideration of Limestabilized Layers in Mechanistic-empirical Pavement Design. The National Lime Association, Arlington, Virginia, USA.

McCallister, L.D. and Petry, T.M., 1992. Leach tests on lime-treated clays. Geotech. Test. J., 15(2).

Milburn, J.P. and Parsons, R., 2004. Performance of soil stabilization agents. Report KU-01-8, Kansas Department of Transportation, Topeka, KS.

Mitchell, J.K., 1986. Practical problems from surprising soil behavior. J. Geotech. Eng-ASCE, 112(3): 255-289.

Mitchell, J.K., 1993. Fundamentals of Soil Behavior, 2nd edn. Wiley, New York.

Mohammed, A. and Vipulanandan, C., 2013. Compressive and tensile behavior of polymer treated sulfate contaminated CL Soil, Geotechnical and Geological Engineering, 32(1), 71-83.

Naeini, S., Ghorbanalizadeh, M., 2010. Effect of wet and dry conditions on strength of silty sand soils stabilized with epoxy resin polymer, Journal of Applied Sciences, 10(22), 2839-2846.

Naeini, S., Naderinia, B., Izadi, E., 2012. Unconfined compressive strength of clayey soils stabilized with waterborne polymer, KSCE Journal of Civil Engineering, 16(6), 943-949.

Nair, S. and Little, D., 2011. Mechanisms of distress associated with sulfate-induced heaving in limetreated soils. Transp. Res. Record: J. Trans. Res. Board, 2212(1): 82-90.

Nalbantoglu, Z. and Tuncer, E.R., 2001. Compressibility and hydraulic conductivity of a chemically treated expansive clay. Can. Geotech. J., 38(1): 154-160.

Newman, K., Tingle, J., 2004. Emulsion polymers for soil stabilization, Airport Technology Transfer Conference, Atlantic City, New Jersey, ABD.

Okucu, A., 1998. Bigadiç ve Turnatepe (Balıkesir) Yörelerindeki Zeolitik ve Perlitik Tüflerin Puzolanik Özellikleri, Balıkesir Üniversitesi Fen Bilimleri Enstitüsü, Doktora Tezi, Balıkesir, 1$54 s$.

Onitsuka, K., Modmoltin, C. and Kouno, M., 2001. Investigation on microstructure and strength of lime and cement stabilized ariake clay. Rep. Fac. Sci. Eng. Saga Univ., 30(1): 49-63.
Puppala, A.J., Ramakrishna, A.M., Hoyos, L.R., 2003. Resilient moduli of treated clays from repeated load triaxial test, Transportation Research Records: Journal of Transportation Research Board, 1821, 68-74.

Push, R., 1979. "Unfrozen water as a function of clay microstructure", Engineering Geology, Vol. 13, pp. 157-162.

Rajasekaran, G. and Rao, S.N., 1997. The microstructure of lime-stabilized marine clay. Ocean Eng., 24(9): 867-878.

Rajasekaran, G. and Rao, S.N., 2002. Compressibility behaviour of lime-treated marine clay. Ocean Eng., 29(5): 545-559.

Ramadas, T., Kumar, N.D. and Yesuratnam, G., 2011. Geotechnical characteristics of three expansive soils treated with lime and flyash. Int. J. Earth Sci. Eng., 4: 46-49.

Rao, S.M. and Shivananda, P., 2005. Compressibility behaviour of lime-stabilized clay. Geotech. Geolog. Eng., 23(3): 309-319.

Rauch, A., Harmon, J., Katz, L., Liljestrand, H., 2002. Measured effects of liquid soil stabilizers on engineering properties of clay, Transportation Research Records: Journal of Transportation Research Board, 1787, 33-41.

Santoni, R., Tingle, J., Webster, S., 2002. Stabilization of silty sand with Nontraditional additives, Transportation Research Records: Journal of Transportation Research Board, 1787, 61-70.

Sebesta, S., 2005. Use of microcracking to reduce shrinkage cracking in cementtreated bases, Transportation Research Records: Journal of Transportation Research Board, 1936, 3-11.

Sherwood, P., 1994. Soil Stabilization with Cement and Lime, Stationary office, London, UK.

Sridharan, A., Sivapullaiah, P. and Ramesh, H., 1995. Consolidation behaviour of lime treated sulphate soils. Proceeding of the International Symposium on Comprssion and Consolidation of Clayey Soils, pp: 183-188.

Tedesco, D.V., 2006. Hydro-mechanical behaviour of lime-stabilised soils. Ph.D. Thesis, University of Cassino. Cassino, Italy.

Terrei, R., Epps J., Barenberg, E., Mitchell, J. and Thompson M., 1984. Soil stabilization in pavement structures-a user's manual. Vol. 2, Moisture design consideration. Federal Highway Administration, Washington, DC.

Thompson, M. and Dempsey, B., 1969. Autogenous healing of lime-soil mixtures. Highway Res. Record, 263: 1-7. 
Thompson, M.R., 1969. Engineering properties of limesoil mixtures. J. Mater., JMLSA, 4(4): 968969.

Tremblay, H., Leroueil, S. and Locat, J., 2001. Mechanical improvement and vertical yield stress prediction of clayey soils from eastern Canada treated with lime or cement. Can. Geotech. J., 38(3): 567-579.

Türköz, M., 2009. Sikıştırılmış Şişen Killerin Mikroyapısal Değişiminde Şişme-Büzülme Çevrimin Etkisi, Journal of Engineering and Architecture Faculty of Eskişehir Osmangazi University, Vol: XXII, No:1.

Voottipruex, P. and Jamsawang, P., 2014. "Characteristics of expansive soils improved with cement and fly ash in Northern Thailand", Geomechanics and Engineering An Int'l Journal, $6(5), 437-453$.
Wang, D., Abriak, N.E., Zentar, R., Chen, W., 2013. Effect of Lime Treatment on Geotechnical Properties of Dunkirk Sediments in France, Road Materials and Pavement Design, 14(3), 485-503.

Wild, S., Kinuthia, J., Robinson, R. and Humphreys, I., 1996. Effects of ground granulated blast furnace slag (GGBS) on the strength and swelling properties of lime-stabilized kaolinite in the presence of sulphates. Clay Miner., 31(3): 423433.

Yang, G., Liu, H., Lv, P. and Zhang B., 2012. Geogridreinforced lime-treated cohesive soil retaining wall: Case study and implications. Geotext. Geomembranes, 35(0): 112-118.

Zandieh, A., Yasrobi, S., 2010. Study of factors affecting the compressive strength of sandy soil stabilized with polymer, Geotechnical and Geological Engineering, 28(2), 139-145. 